\title{
Invitro Antibacterial Activity of Ethanolic Extracts of Dietary Spices Against Clinical Isolates
}

\author{
Tanveer Abbas ${ }^{1, *}$, Faryal Liaquat ${ }^{1}$, Najma Shaheen ${ }^{2}$, Iqbal Azhar ${ }^{2}$, and Zafar Alam Mehmood ${ }^{3}$ \\ ${ }^{I}$ FSRG, Department of Microbiology, University of Karachi, 75270, Karachi, Pakistan. \\ ${ }^{2}$ Department of Pharmacognosy, Faculty of Pharmacy, University of Karachi, 75270, Karachi Pakistan. \\ ${ }^{3}$ Colorcon Limited, Crossways, Victoryway, Kent, Dartford, England.
}

\begin{abstract}
The invitro antibacterial activity of ethanolic extracts of three dietary spices Coriandum sativum (Coriander), Curcuma longa (Turmeric) and Capsicum annuum (Red chili) were investigated by well diffusion method against clinical isolates which include Gram positive (Enterrococcus spp., Staphlococcus aureus) and Gram negative (Pseudomonas aeruginosa, Salmonella typhi, Escherichis coli, Proteus spp., Klebsiella pneumonia and Acinetobacter baumannii) as well as by minimal inhibitory concentration and by microdilution method. Moreover, killing time of each extract was also calculated against Escherichia coli.
\end{abstract}

Keywords: Dietary spices, ethanolic, extracts, time kill assay. doi.org/10.21089/njhs.11.0011

\section{INTRODUCTION}

Spices are extracted from plants. They could be seeds, fruits, roots, barks, buds or other vegetable substance, considered as a core part to enhance flavor, color and aroma of food. Conventionally, flavor spices as well are used as cost effective preservatives as well. Additionally, they possess antimicrobial capabilities and medication values for treatment of common disturbances and ailments $[1,2]$. To date various spices holding antibacterial activity towards pathogens are studied and documented [1,2]. Furthermore, safest use of these dietary spices lead researchers to spot and study more active compounds [3-5]. In this modern era the interest in using natural substances has increased, due to biological functions and synergistic affects which are likely to shield the body against variety of infections. Spices are efficient anti-oxidants, anti-cancer agent, digestion facilitators and much more $[6,7,9,10]$.

Coriandum sativum (Coriander) belongs to Family Apiaceae. Apart from being used as a spice it is widely used as a herb also. Its seed oil is one of the major oil in world market [6, 11-12].

Curcuma longa (Turmeric) belongs to Family Zingiberacea, its polyphenolic compound 'Curcumin' has been recognized

*Address correspondence to this author at the FSRG, Department of Microbiology, University of Karachi, 75270, Karachi, Pakistan.

E-mail: taabbas@uok.edu.pk as an antimicrobial and an anticancer agent $[8,10]$. It holds potent anti-oxidant and anti-inflammatory characteristics [4].

Capsicum annuum (Red chili) belongs to Family Solanacea, it holds 'Capsaicin' that is medically very important and is used in preparation of ointments [13, 14]. This study explores the antimicrobial activity of ethanolic extracts from aromatic spices from available plants of Pakistan against clinical isolates.

\section{MATERIALS AND METHODS}

Microbial Strains: Eight clinical isolates were used in this study provided by the Clinical Laboratory. Of them two were Gram positive (Enterrococcus spp., Staphlococcus aureus) and six were Gram negative (Pseudomonas aeruginosa, Salmonella typhi, Escherichia coli, Proteus spp., Klebsiella pneumoniae and Acinetobacter baumannii).

Sample Purchasing And Authentication: All spices were identified and purchased from local market. Their voucher specimen numbers are deposited in the Department of Pharmacognosy, University of Karachi.

Preparation Of Extract: Spice Samples were soaked in ethanol separately at room temperature for fifteen days. After fifteen days all the samples were filtered and extracts were evaporated by using rotary evaporator to obtain semidried extracts.

Preparation Of Inoculum: Pure culture of test organisms were streaked onto Nutrient Agar Medium. Isolated Colonies

www.njhsciences.com 
of the test organisms were transferred in sterile PBS and turbidity of the suspensions were adjusted to 0.5
McFarland's Standard to get initial count of $10^{8} \mathrm{cfu} / \mathrm{ml}$ and further diluted up to $10^{6} \mathrm{cfu} / \mathrm{ml}$.

Table 1. Zone of inhibition in diameter, (-) means no inhibition, Berberis vulgaris as a positive control, coriander versus control is significant correlation whereas Turmeric and Red chili is insignificant. Staph. aureus-Staphlococcus-aureus; P. aeruginosa-Pseudomonas aeruginosa; S. typi-Salmonella typhi; A. baumannii-Acinetobacter baumanii; K. pneumoniaeKlebsiella pneumonia; E. coli-Escherichia coli.

\begin{tabular}{|c|c|c|c|c|}
\hline Clinical Isolates & Coriander & Red Chili & Turmeric & B.Vulgaris Positive Control \\
\hline S. aureus & $11 \mathrm{~mm}$ & - & $13 \mathrm{~mm}$ & $1 \mathrm{~mm}$ \\
\hline Enterococcus spp. & $12 \mathrm{~mm}$ & - & - & $19 \mathrm{~mm}$ \\
\hline P.aeruginosa & - & $10 \mathrm{~mm}$ & $8 \mathrm{~mm}$ & $15 \mathrm{~mm}$ \\
\hline E. coli & $11 \mathrm{~mm}$ & 12 & $10 \mathrm{~mm}$ & $15 \mathrm{~mm}$ \\
\hline S. typhi & $14 \mathrm{~mm}$ & $9 \mathrm{~mm}$ & $14 \mathrm{~mm}$ & $10 \mathrm{~mm}$ \\
\hline A. baumanii & - & $16 \mathrm{~mm}$ & - & $11 \mathrm{~mm}$ \\
\hline K. pneumonae & $9 \mathrm{~mm}$ & $11 \mathrm{~mm}$ & $9 \mathrm{~mm}$ & $1 \mathrm{~mm}$ \\
\hline Proteus spp. & $10 \mathrm{~mm}$ & & & \\
\hline
\end{tabular}

Table 2. Minimum inhibitory concentration v/v so it is expressed in $\%$ and $\mathrm{w} / \mathrm{v}$ in $\mathrm{mg} / \mathrm{ml}$, significant correlation for all three ethanolic extracts versus positive control. S.aureus-Staphlococcus aureus; P. aeruginosa-Pseudomonas aeruginosa; S. typiSalmonella typhi; A. baumannii-Acinetobacter baumanii; K. pneumoniae-Klebsiella pneu-moniae; E. coli-Escherichia coli.

\begin{tabular}{|c|c|c|c|c|}
\hline Clinical Isolates & Coriander & Turmeric & Red Chili & B.Vugaris Positive Control \\
\hline S.aureus & $2.5 \%$ & $5 \%$ & $5 \%$ & $25 \%$ \\
\hline P.aeruginosa & $2.5 \%$ & $5 \%$ & $5 \%$ & $6.25 \%$ \\
\hline S.typhi & $5 \%$ & $5 \%$ & $0.625 \%$ & $3.1 \%$ \\
\hline E.coli & $2.5 \%$ & $2.5 \%$ & $0.625 \%$ & $6.25 \%$ \\
\hline Enterococcus spp. & $1.25 \%$ & $5 \%$ & $0.625 \%$ & $12.5 \%$ \\
\hline Proteus spp. & $2.5 \%$ & $2.5 \%$ & $0.625 \%$ & $1.5 \%$ \\
\hline K.pneumoniae & $1.25 \%$ & $5 \%$ & $5 \%$ & $3.1 \%$ \\
\hline A.baumanii & 0.625 & $5 \%$ & 5 \\
\hline
\end{tabular}

\section{ANTIMICROBIAL ACTIVITY ASSAY}

In vitro, antibacterial activity of each ethanolic extracts was investigated against the test strains. Two antibacterial sensitivity assays i.e.; Agar Well Diffusion Assay and Minimum Inhibitory Concentration were used to determine the growth inhibition [18, 19]. Additionally, killing time assay of each extract in opposition to Escherichia coli was also investigated. Berberis vulgaris was used as a positive standard throughout the study. The stock solution of each extract was prepared in DMSO.

Agar Well Diffusion Assay: The screening of antibacterial activity of three selected spices was carried out using agar 
Well Diffusion Assay. The adjusted culture was used to make lawn on Mueller Hinton Agar media plate $\left(\right.$ Oxoid $^{\circledR}$ ) using sterile cotton swab. $7 \mathrm{~mm}$ sterile borer was used to make a well then $100 \mu 1$ of $10 \%$ ethanolic extract was added to each well. The plates were incubated at $37^{\circ} \mathrm{C}$ for 24 hours. The sensitivity was determined on the basis of zone of inhibition around the well. This test was run in triplicate and repeated, therefore, $\mathrm{n}=6$.

Minimum Inhibitory Concentration: To identify sensitivity of microbes towards ethanolic extracts, MIC was measured by microdilution method using 96 microtitre plate. The extracts were serially diluted in 1:2 dilutions according to CLSI recommendations. $10 \mu \mathrm{l}$ culture was added in each well, positive and negative controls were also run and plates were incubated at $37{ }^{\circ} \mathrm{C}$ for 24 hours. Microdilution Method was individually followed for all three samples against provided isolates. Plates were read by ELISA plate reader.
Time Kill Assay: This assay was performed using Escherichia coli to record the time taken to enforce the killing effects. The experiment was performed by inoculating test organism in nutrient broth and incubated at $37^{\circ} \mathrm{C}$ for 24 hours. It was matched with 0.5 McFarland's Index and broth culture was diluted to $10-3$ dilution. $1 \mathrm{ml}$ of culture was added with $0.1 \mathrm{ml}$ of extract in cuvettes. Optical Density (OD) was measured at intervals of $0 \mathrm{~min}, 30 \mathrm{~min}, 60 \mathrm{~min}$, $120 \mathrm{~min}, 240 \mathrm{~min}$ and $1440 \mathrm{~min}$.

\section{RESULT AND DISCUSSION}

The antibacterial activities of ethanolic extracts in term of zone of inhibition and minimum inhibitory concentration are reported in Table $\mathbf{1}$ and $\mathbf{2}$.

The ethanolic extract of Curcuma longa (Turmeric) showed antibacterial activity against Escherichia coli with zone diameter of $8 \mathrm{~mm}$ and MIC $2.5 \%$, Acinetobacter baumannii

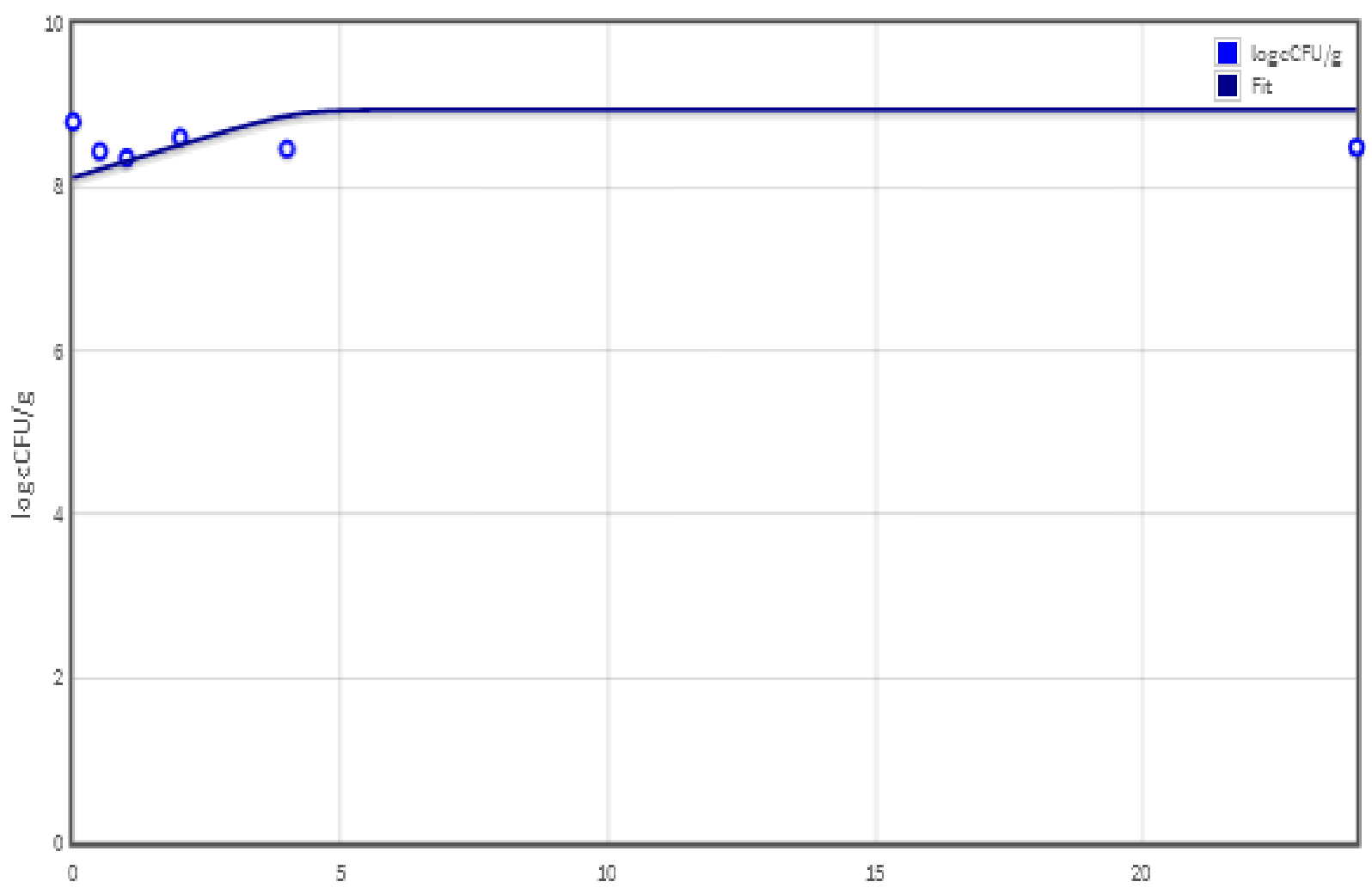

Fig. (1). Time kill of E.coli in ethanolic extract of Red chili fitted in DmFit (Dynamic modeling fit) R2=0.701 and SE of fit 0.208 .

$14 \mathrm{~mm}$ with MIC 5\%, Staphylococcus aureus $13 \mathrm{~mm}$ with MIC 5\%, Pseudomonas aeruginosa $10 \mathrm{~mm}$ with MIC $2.5 \%$ and Salmonella typhi $10 \mathrm{~mm}$ MIC $5 \%$, while Klebsiella pneumoniae and Enterrococcus spp. were not sensitive towards Turmeric.

Coriandum sativum (Coriander) showed antimicrobial activity against all organism except Acinetobacter baumanii and Pseudomonas aeruginosa, Staphylococcus aureus $11 \mathrm{~mm}$ with MIC 2.5\%, Salmonella typhi $14 \mathrm{~mm}$ with MIC 5\%, Escherichia coli $11 \mathrm{~mm}$ with MIC $2.5 \%$ Enterrococcus spp. $12 \mathrm{~mm}$ MIC $1.25 \%$, Proteus spp. 10mm MIC $2.5 \%$, Klebsiella pneumoniae 9mm MIC 1.25\%.

Capsicum annuиm (Red chili) showed antibacterial activity against Salmonella typhi with zone diameter $12 \mathrm{~mm}$ MIC $0.625 \%$, Escherichia coli $10 \mathrm{~mm}$ MIC $0.625 \%$, Proteus spp. $11 \mathrm{~mm}$ MIC $0.625 \%$, K. pneumoniae $16 \mathrm{~mm}$ MIC $0.625 \%$ and 
Acinetobactor baumannii $9 \mathrm{~mm}$ with MIC 5\%. Some of the isolates failed to show results in well diffusion assay whereas, their minimum inhibitory concentration was determined so it may be due to improper diffusion of extracts in media and might be human error. Pearson's Correlation of zone of inhibition and minimum inhibitory concentration of each ethanolic extracts was calculated versus positive control. Zone of inhibition of coriander extract indicated significant correlation whereas turmeric and red chilli showed insignificant correlation while minimum inhibitory concentration correlation was significant for all three ethanolic extracts.

Time Kill Assay: The assay was performed using Escherichia coli to analyze the time taken by test compound to exert its killing effect. Killing time of each extract was compared with the positive control, Berberis vulgaris Fig. (4). Graphs were plotted by using DMFit (dynamic modeling Fit) [20]. In the presence of test compound Capsicum annuum (Red chili) the $\log \mathrm{CFU} / \mathrm{ml}$ was 8.80 at $0 \mathrm{~min}$. The organism started to grow but compound started exerting its effect and slight decrease was observed after 30min till 1440min as shown in Fig. (1). In the presence of Curcuma longa (Turmeric) the $\log \mathrm{CFU} / \mathrm{ml}$ was 8.68 at 0 mim later on a decrease was seen in viable counts of Escherichia coli as shown in graph Fig. (2). While Coriandum sativum (Coriander) extracts, initially had $\log \mathrm{CFU} / \mathrm{ml}$ was 8.86 which started decreasing after 30min till end as shown in Fig. (3).

Invitro activities of these plant extracts showed good antibacterial activity not in favor of pathogenic microorganism. It can be claimed that folk medicine can be used as effectively as modern medicine to combat infectious microbes. [15] Pseudomonas aeruginosa, a notorious organism known for its resistance to various antibiotics and Acineto bactorbaumannii, [16].

Multi drug resistant (MDR), is an important cause of nosocomial infections which is also affected by ethanolic extracts of these spices and witnessed greater antibacterial activity. Although there is a great achievement and advancement in medicine technology but people are realizing to use natural products to ensure safety [17]. Interest in using natural products has been revived as a result of antimicrobial resistance to various drugs.

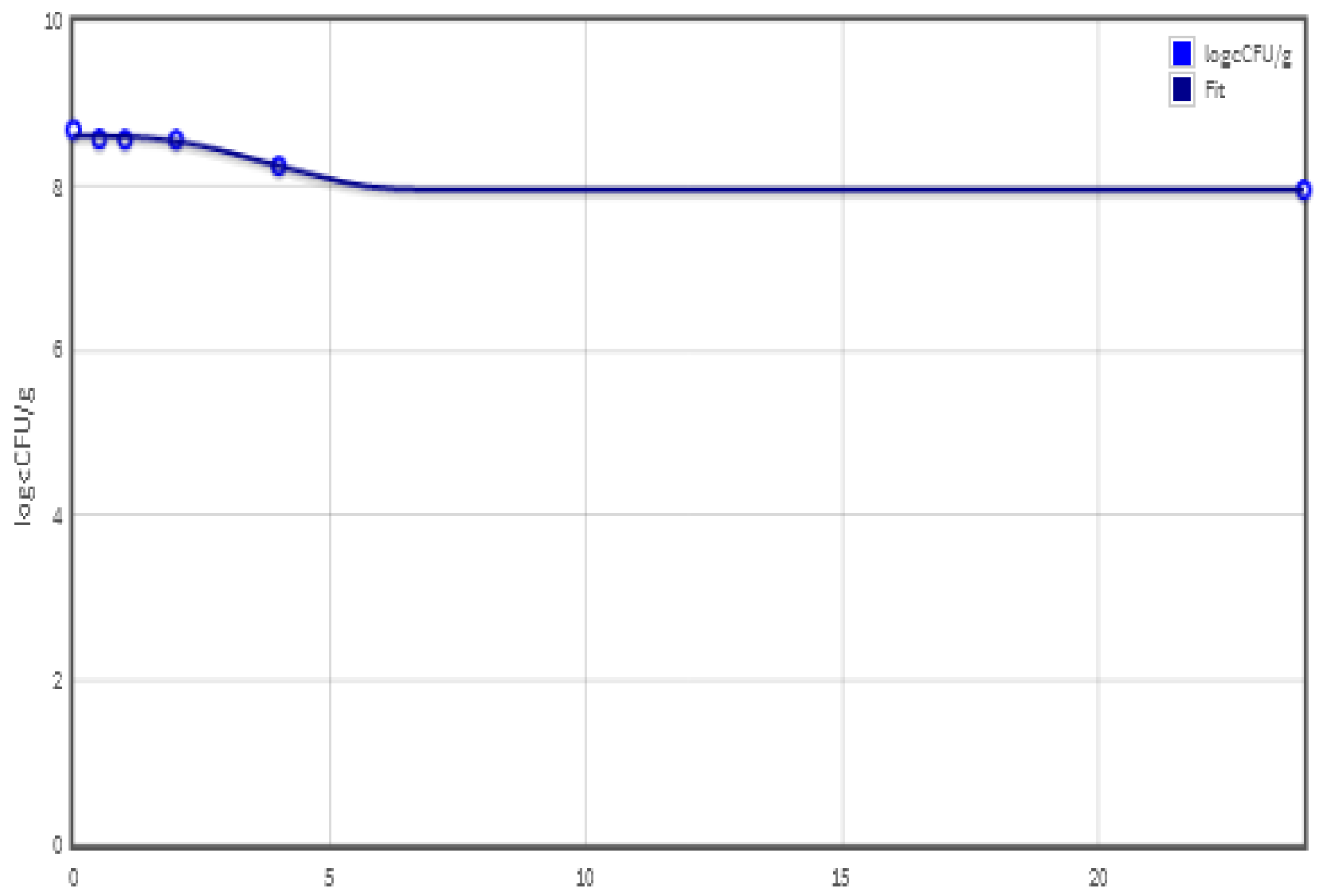

Fig. (2). Time kill of E.coli in ethanolic extract of turmeric fitted in DmFit (Dynamic modeling fit) R2=0.947 and SE of fit 0.0638 . 


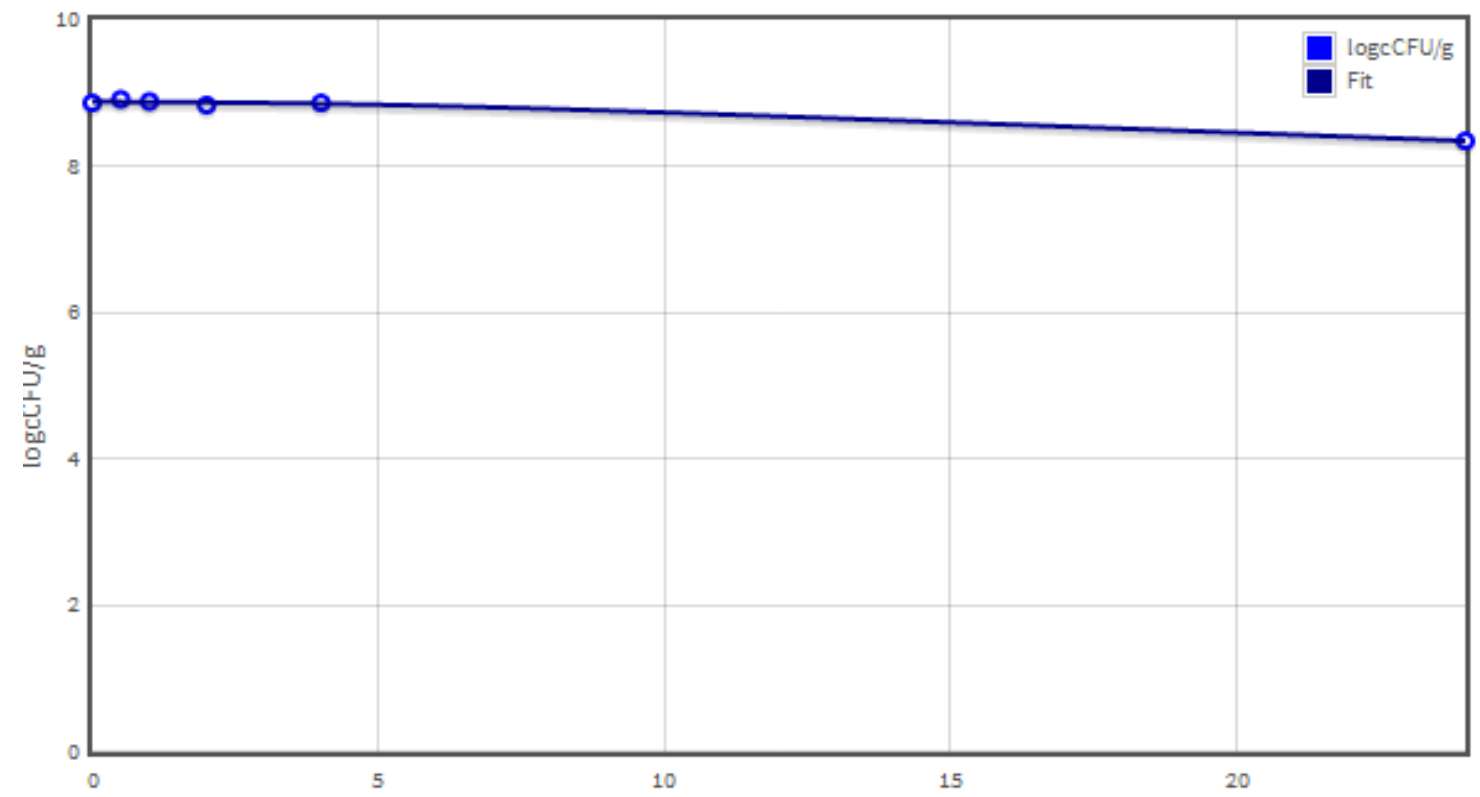

Fig. (3). Time kill of E.coli in ethanolic extract of Coriander fitted in DmFit (Dynamic modeling fit) R2=0.978 and SE of fit 0.032 .

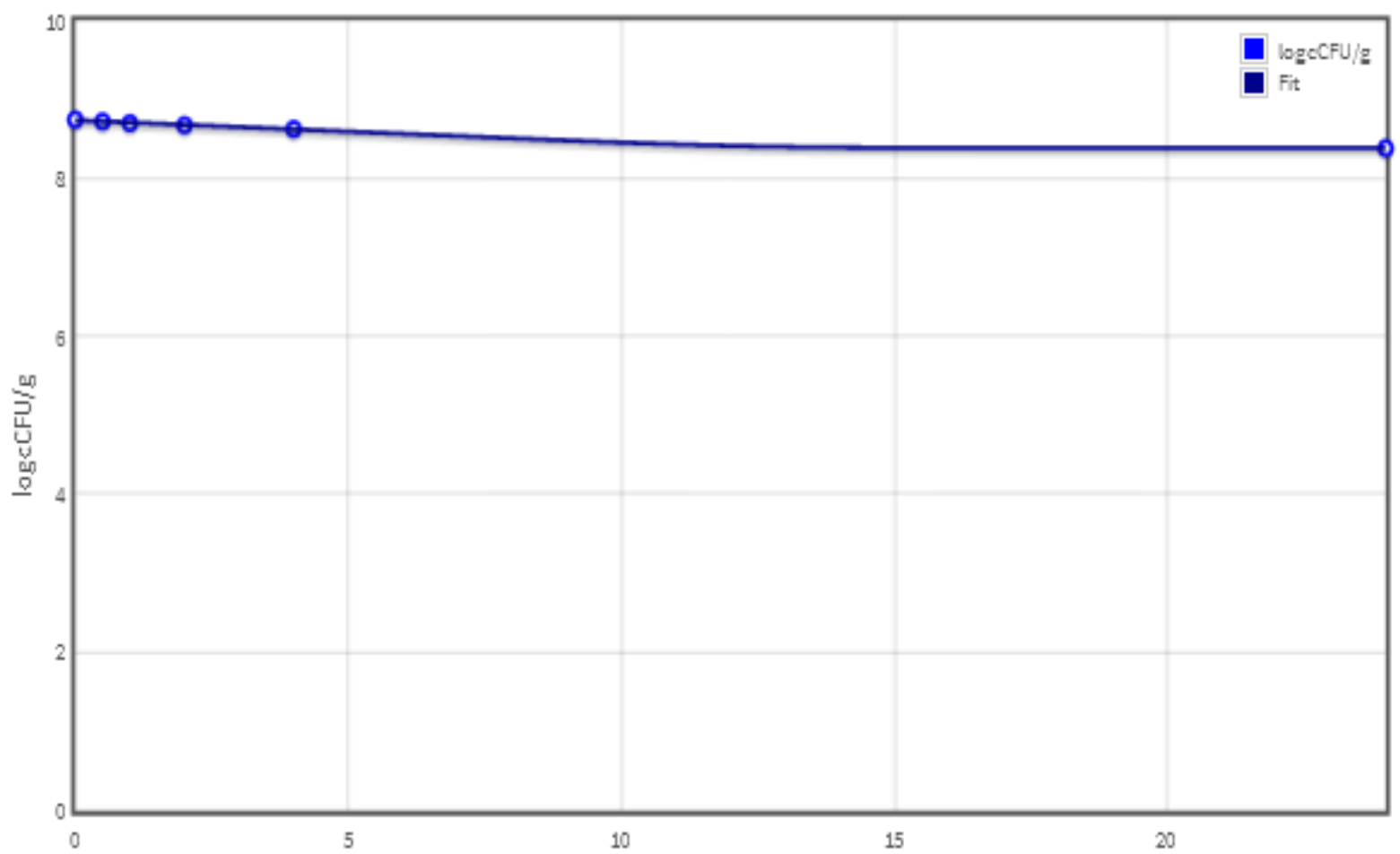

Fig. (4). Time kill of Berberis vulgaris positive control fitted in DmFit (Dynamic modeling fit) R2=0.997 and SE of fit 0.00748 .

\section{CONCLUSION}

This study witnessed the antimicrobial potential of Coriandum sativum (Coriander), Curcuma longa (Turmeric) and Capsicum annuиm (Red chili). Their effective use can be made for treatment of certain infections and it is exposed that they have a significant scope towards development of herbal antimicrobial agents. 


\section{ACKNOWLEDGEMENT}

I am thankful to Dean Faculty Of Science, University of Karachi, Karachi. 75270, Pakistan, for providing financial support for the recent research.

\section{CONFLICT OF INTEREST}

Declared none.

\section{REFERENCES}

[1] Shete, H. G., and Chitanand, M. P. Antimicrobial activity of some commonly used Indian Spices. Int. J. Curr. Microbiol. App. Sci., 2014; 3(8): 765-770.

[2] Joe, M. M., Jayachitra, J., and Vijayapriya, M. Antimicrobial activity of some common spices against certain human pathogens. J. Medicinal Plants Res., 2009; 3(12): 1134-1136.

[3] Abdollahzadeh, E., Rezaei, M., and Hosseini, H. Antibacterial activity of plant essential oils and extracts: The role of thyme essential oil, nisin, and their combination to control Listeriamonocytogenes inoculated in minced fish meat. Food Cont., 2014; 35(1): 177-183.

[4] Liju, V. B., Jeena, K., and Kuttan, R. Chemopreventive Activity of Turmeric Essential Oil and Possible Mechanisms of Action.Asian Pacific journal of cancer prevention: APJCP, 2014; 15(16): 6575.

[5] Liju, V. B., Jeena, K., and Kuttan, R. Chemopreventive Activity of Turmeric Essential Oil and Possible Mechanisms of Action.Asian Pacific journal of cancer prevention: APJCP, 2014; 15(16): 6575.

[6] Suvarna, R., Bhat, S. S., and Hegde, K. S. Antibacterial Activity of Turmeric against Enterococcusfaecalis an in vitro Study. Int. J. Curr. Microbiol. App. Sci., 2014; 3(2): 498-504.

[7] Berrington, D., and Lall, N. Anticancer activity of certain herbs and spices on the cervical epithelial carcinoma (HeLa) cell line. Evidence-Based Complementary and Alternative Medicine, 2012.

[8] Rao, N., and Mittal, S. An in vitro Evaluation of the Antimicrobial Activity of Curcuma longa against Selected Pathogenic Microorganisms. Res. J. Sci. Technol., 2014; 6(2): 71-74.

[9] Ichwan, S. J., Al-Ani, I. M., Bilal, H. G., Suriyah, W. H., Taher, M., and Ikeda, M. A. Apoptotic Activities of Thymoquinone, an
Active Ingredient of Black Seed (Nigella sativa), in Cervical Cancer Cell Lines. Chinese J. Physiol., 2014; 57(5): 249-255.

[10] Mehta, H. J., Patel, V., and Sadikot, R. T. Curcumin and lung cancer-a review. Targeted Oncol., 2014; 9(4): 295-310.

[11] Bhat, S., Kaushal, P., Kaur, M., and Sharma, H. K. Coriander (Coriandrumsativum L.): Processing, nutritional and functional aspects. Afri. J. Plant Sci., 2014; 8(1): 25-33.

[12] SHanafi, R., Sobeh, M., L Ashour, M., Z El-Readi, M., Y Desoukey, S., Niess, R., and Wink, M. Chemical Composition and Biological Activity of Essential Oils of Cumin and Coriander Fruits from Egypt. Nat. Prod. J., 2014; 4(1): 63-69.

[13] Omolo, M. A., Wong, Z., Mergen, A. K., Hastings, J. C., Le, N. C., Reiland, H. A., and Baumler, D. J.. Antimicrobial Properties of Chili Peppers. J. Infect. Dis. Ther., 2014.

[14] Barbero, G. F., Liazid, A., Azaroual, L., Palma, M., and Barroso, C. G. (2015). Capsaicinoid contents in peppers and pepper-related spicy foods. Int. J. Food Prop., (just-accepted).

[15] Martins, N., Ferreira, I. C., Barros, L., Carvalho, A. M., Henriques, M., and Silva, S. Plants used in folk medicine: The potential of their hydromethanolic extracts against Candida species. Industrial Crops and Products, 2015; 66, 62-67.

[16] Jayamani, E., Rajamuthiah, R., Larkins-Ford, J., Fuchs, B. B., Conery, A. L., Vilcinskas, A., and Mylonakis, E. Insect-derived Cecropins Display Activity Against Acinetobacterbaumannii in a Whole-Animal High-Throughput Caenorhabditis-elegans Model. Antimicro. Agents and Chemother., AAC-04198, 2015.

[17] Graham, T. Complimentary Medicine: A Natural and Healthy Approach to Stone Prevention. In Kidney Stone Disease. Springer International Publishing, 2015; 181-185.

[18] Clinical and Laboratory Standards Institute. Performance standards for antimicrobial disk and dilution susceptibility tests for bacteria isolated from animals; approved standard- $3^{\text {rd }}$ edition CLSI Document M31-A3, 2008; 28: 65.

[19] Clinical and Laboratory Standards Institute. Methods forantimicrobial dilution and disk susceptibility testing of infrequently isolated or fastidious bacteria; approved guideline-2nd edition. CLSI Document M45-A2 2010; 30: 18.

[20] www.combase.cc/DMFit.aspxs 